\title{
Diagnóstico por Imagem na Avaliação da Anemia Falciforme
}

\section{Imaging Diagnosis on the Evaluation of Sickle-Cell Anemia}

\author{
Matiko Yanaguizawa $^{(1)}$, Gustavo Sobreira Taberner ${ }^{(1)}$, Fabiano Nassar de Castro Cardoso ${ }^{(1)}$, \\ Jamil Natour ${ }^{(2)}$, Artur da Rocha Corrêa Fernandes ${ }^{(1)}$
}

\section{INTRODUÇÃO}

A anemia falciforme é uma anemia hemolítica hereditária, caracterizada pela presença de células vermelhas com formato anormal (forma de foice), que são removidas da circulação e destruídas. A alteração de base nas células vermelhas é a presença de uma hemoglobina anormal ( $\mathrm{HbS})$, que quando desoxigenada, se torna relativamente insolúvel, formando agregados que distorcem sua forma e impedem seu fluxo no interior dos vasos sangüíneos ${ }^{(1)}$.

A denominação anemia falciforme é reservada para a forma que ocorre nos indivíduos homozigotos para a hemoglobina S (SS), havendo ainda as formas heterozigotas, na qual o gene da $\mathrm{HbS}$ combina-se com a hemoglobina normal ( $\mathrm{HbA}$ ) ou com outras formas anormais da hemoglobina ( $\mathrm{HbC}, \mathrm{HbD}$, betatalassemia, entre outras) $)^{(2)}$.

O objetivo deste artigo é discutir as principais indicações e contribuições dos métodos de imagem na avaliação dos pacientes com anemia falciforme, enfocado nas manifestações do sistema musculoesquelético.

\section{EPIDEMIOLOGIA}

Estima-se que existam mais de 2 milhões de portadores da HbS no Brasil, sendo mais de 8 mil afetados com a forma homozigótica (HbSS). Estima-se também o nascimento de 700 a 1.000 novos casos por ano das doenças falciformes ${ }^{(2)}$.

\section{DIAGNÓSTICO}

O diagnóstico é feito por meio de técnicas eletroforéticas, hemograma e dosagens de hemoglobina fetal ${ }^{(2)}$.

O papel dos métodos de imagem na avaliação desses pacientes está relacionado, principalmente, ao diagnóstico e ao acompanhamento das complicações que podem surgir durante a vida, sobretudo aquelas de natureza vasooclusiva $^{(1)}$.

\section{MANIFESTAÇÕES CLÍNICAS}

Para a grande maioria dos pacientes, as complicações vasooclusivas são muito mais problemáticas do que a anemia em si, que normalmente é bem tolerada ${ }^{(1)}$.

Entre as manifestações não relacionadas ao sistema musculoesquelético, podem-se citar como principais: a síndrome pulmonar aguda, necrose papilar, insuficiência renal, infarto ou seqüestro esplênico e complicações cerebrovasculares $^{(3)}$.

O envolvimento do sistema osteoarticular é um dos mais comuns nos pacientes com anemia falciforme e inclui desde a hiperplasia medular reativa ao quadro anêmico até as complicações como infartos ósseos e infecções ${ }^{(1,4)}$.

\section{HIPERPLASIA MEDULAR REATIVA}

Em indivíduos sadios, a medula óssea vermelha se converte em medula gordurosa durante a infância, iniciando-se nas regiões distais do esqueleto apendicular e caminhando para as regiões proximais. Esse processo se inicia ao nascimento e por volta da segunda década de vida, a medula vermelha residual pode persistir na pelve, no esterno, na costelas e nos corpos vertebrais ${ }^{(1)}$.

Nos pacientes com anemia falciforme, o espaço medular tende a preservar a medula vermelha, podendo sofrer expansão devida ao aumento da demanda hematopoética causado pela anemia.

A expansão da medular óssea pode ser evidente no crânio por espessamento da díploe. À radiografia simples, um aspecto de múltiplas estriações perpendiculares pode ser observado (aspecto de "cabelo arrrepiado").

Declaramos a inexistência de conflitos de interesse.

1. Departamento de Diagnóstico por Imagem da Universidade Federal de São Paulo (UNIFESP).

2. Disciplina de Reumatologia da UNIFESP.

Endereço para correspondência: Artur da Rocha Corrêa Fernandes, DDI/UNIFESP, Rua Botucatu, 740, 04023-900, São Paulo, SP, e-mail: artur_personal@yahoo.com 
O predomínio da medula óssea vermelha apresenta-se à ressonância magnética como um hipossinal difuso da medular óssea nas seqüências ponderadas em $\mathrm{Tl}$, onde se esperaria um hipersinal de gordura (Figura 1 ).

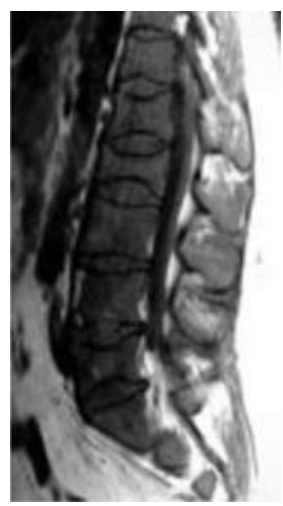

Figura 1 - Ressonância magnética de coluna lombar de paciente com anemia falciforme, sequêencia ponderada em T1 no plano sagital. Hipossinal difuso da medular óssea dos corpos vertebrais compatível com hiperplasia medular reativa, e depressões centrais de alguns platôs vertebrais ("vértebra em H").

\section{INFARTOS ÓSSEOS}

As crises vasooclusivas afetam virtualmente todos os pacientes com anemia falciforme, com início na infância e recorrências durante toda a vida ${ }^{(1)}$. Embora possam ocorrer em qualquer órgão, os infartos são particularmente comuns na medular óssea e nas epífises.

O infarto ósseo pode manifestar-se clinicamente com dor, edema e eritema locais ou pode ser silencioso, sendo o achado de imagem acidental. Nos casos sintomáticos, febre e leucocitose também podem estar presentes, dificultando o diagnóstico diferencial com processos infecciosos.

O envolvimento isquêmico de músculos e fáscias é um achado menos comum nesses pacientes, mas pode ser encontrado. A mionecrose pode causar alteração do tamanho e da forma da musculatura afetada, que se apresentará com aumento do sinal nas imagens de ressonância magnética ponderadas em T2 (Figura 2). Essa alteração é caracterizada por dor no segmento afetado, além de poder estar associada $\mathrm{a}$ alterações laboratoriais relacionadas à mionecrose, como aumento de $\mathrm{CPK}^{(5)}$.

\section{INFARTOS MEDULARES}

As radiografias simples geralmente são normais na fase aguda dos infartos ósseos medulares. Alguns meses depois, podem mostrar áreas radioluscentes bem definidas, seguidas por áreas luscentes subcondrais em forma de arco e intramedulares, com halo esclerótico ${ }^{(1,6)}$.

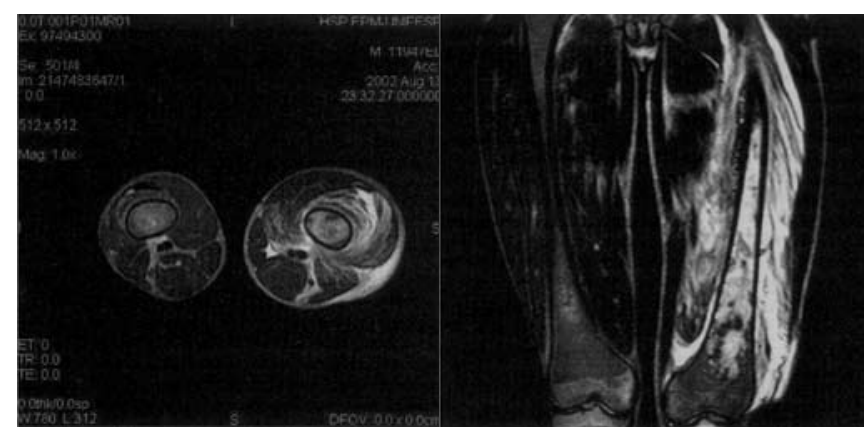

Figura 2 - Ressonância magnética de coxas, seqüências ponderadas em T2 nos planos axial e coronal. Aumento do sinal (edema) dos músculos vasto lateral e bíceps femoral da coxa esquerda, além de alteração do sinal da medular óssea do fêmur deste lado, caracterizando infarto muscular e infarto ósseo.

A ressonância magnética é um método de imagem bastante sensível para detectar o infarto ósseo, podendo identificar anormalidades dentro de poucos dias após o evento isquêmico. As áreas de infarto aparecem com alto sinal nas imagens ponderadas em T2 ou STIR (seqüências sensíveis a líquido) e não apresentam realce após injeção endovenosa do meio de contraste (Figuras 3 e 4$)^{(7)}$. Com o passar do tempo, essas áreas passam a ter baixo sinal em todas as sequiências em razão da fibrose e da esclerose. Alterações de sinal do periósteo e das partes moles adjacentes também podem estar presentes, dificultando ainda mais o diagnóstico diferencial com osteomielite ${ }^{(8,9)}$.

$\mathrm{Na}$ coluna vertebral, as áreas de infarto ósseo podem atingir as porções centrais dos platôs vertebrais com subseqüente supercrescimento das porções adjacentes. Isso acarreta uma deformidade característica dos corpos vertebrais afetados ("vértebra em H"), com depressão central dos platôs, que é facilmente identificada em radiografias simples $^{(1,3,6)}$ (Figuras 1 e 5).

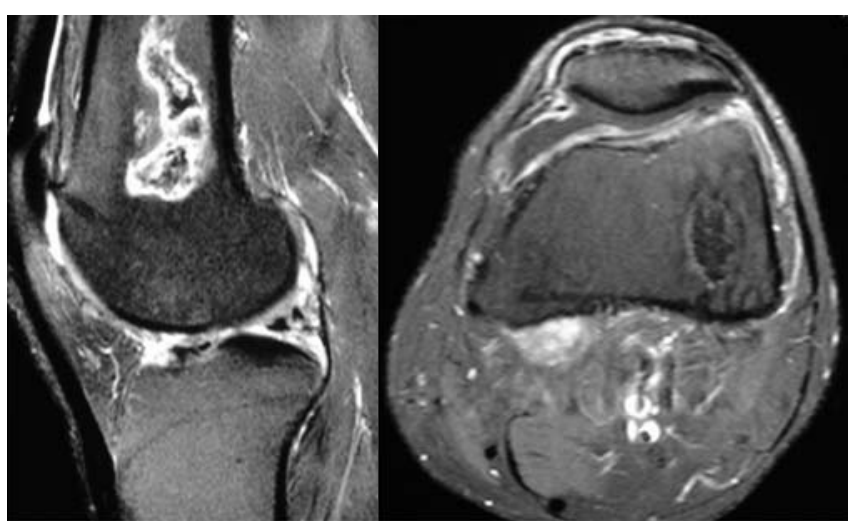

Figura 3 - Ressonância magnética de joelho esquerdo, seqüência ponderada em T2 no plano sagital e em T1 pós-contraste axial. Área geográfica com hipossinal central e alto sinal perifericamente na metáfise distal do fêmur, que não sofre realce após injeção endovenosa do meio de contraste, compatível com infarto medular. 


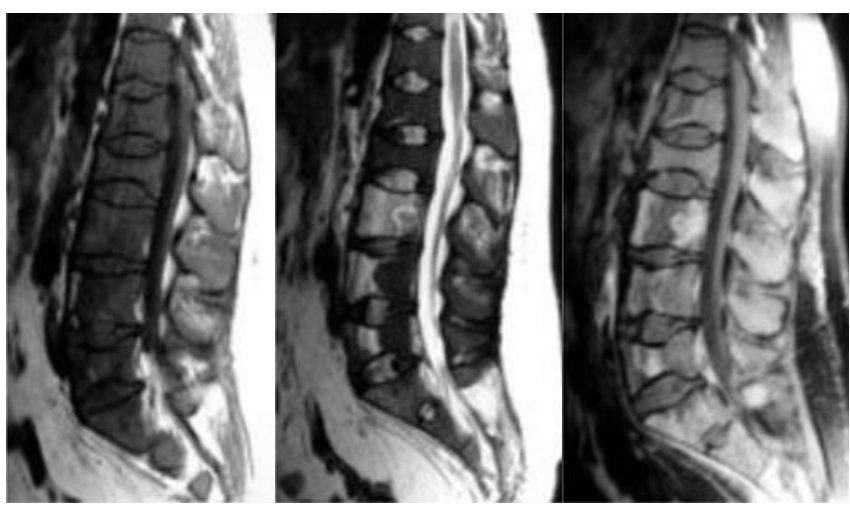

Figura 4 - Ressonância magnética de coluna lombar, seqüências ponderadas em T1, T2 e T1 pós-contraste no plano sagital. Hipossinal difuso da medular óssea dos corpos vertebrais na seqüência ponderada em T1. Áreas focais nos corpos vertebrais de L3 e L4 com hipossinal em T1, hipersinal em T2 e sem realce após injeção endovenosa do meio de contraste, compatíveis com infartos medulares.
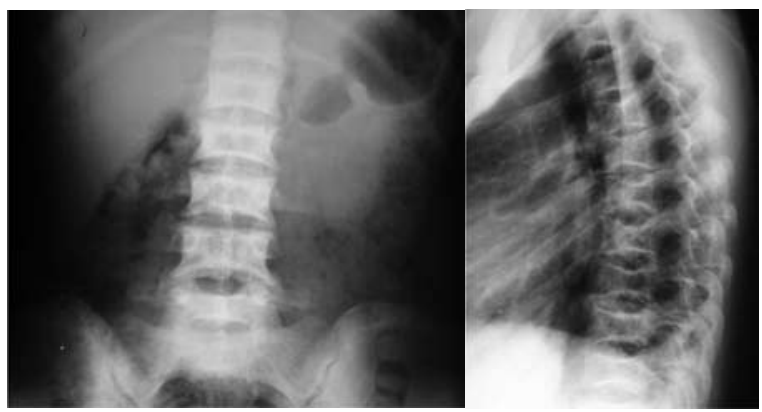

Figura 5 - Radiografias simples da coluna lombar (ântero-posterior) e torácica (perfil). Depressão central dos platôs vertebrais (aspecto denominado "vértebra em H").

\section{INFARTOS EPIFISÁRIOS}

Embora possam ocorrer em qualquer osso, têm predileção pelo úmero e fêmur proximais.

A anemia falciforme é a causa mais comum de osteonecrose do quadril em crianças, e aproximadamente metade dos pacientes a desenvolverá até os 35 anos de idade ${ }^{(1)}$.

Inicialmente, quando o paciente se queixa de dor, as radiografias simples são normais. Nesse momento, as imagens de ressonância magnética ponderadas em T2 ou STIR podem mostrar áreas de alto sinal na medular óssea compatível com edema (Figura 6). As radiografias subseqüentes mostram um aspecto moteado das epífises, áreas luscentes subcondrais e finalmente achatamento com colapso da superfície $\operatorname{articular}^{(1)}$.

\section{DACTILITE}

Em crianças com menos de 4 anos de idade (particularmente entre 1 e 2 anos), as crises vasooclusivas, freqüentemente, ocorrem nos pequenos ossos das mãos e dos pés (síndrome mão-pé).

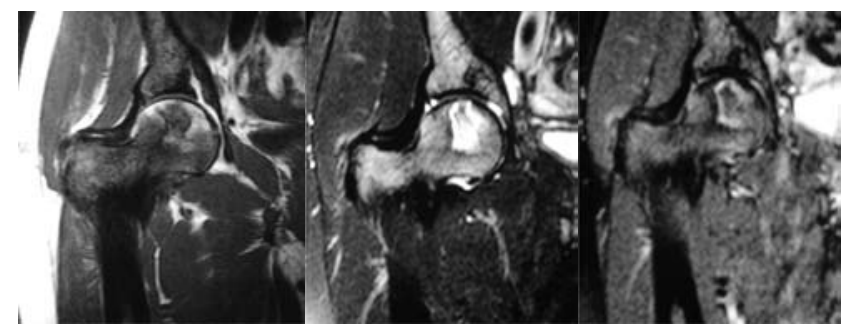

Figura 6 - Ressonância magnética do quadril direito, sequiências ponderadas em T1, T2 e T1 pós-contraste no plano coronal. Hipossinal difuso da medular óssea na seqüência ponderada em T1. Área geográfica de hipossinal em T1, hipersinal heterogêneo em T2, com realce periférico após injeção do meio de contraste endovenoso, compatível com osteonecrose da cabeça femoral.

As radiografias iniciais são freqüentemente normais. Em aproximadamente 10 dias, periostite com neoformação óssea subperiosteal é tipicamente evidente (Figura 7). Há também afilamento cortical e uma aparência moteada da medular óssea ${ }^{(1,10)}$.

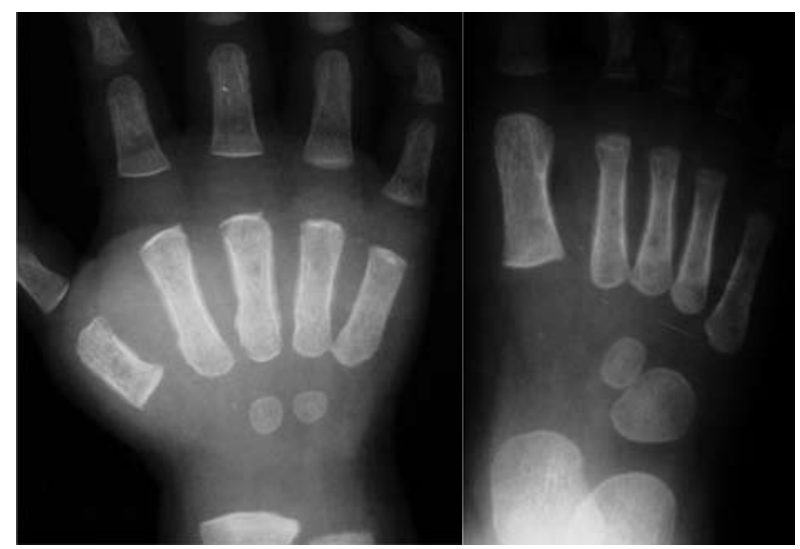

Figura 7 - Síndrome mão-pé: radiografias simples de criança com 11 meses, portadora de anemia falciforme e com queixa de dor e edema nas mãos e pés demonstram periostite nos metacarpos e metatarsos

\section{OSTEOMIELITE}

A susceptibilidade aumentada a infecções dos pacientes com anemia falciforme, incluindo a osteomielite, está relacionada a vários mecanismos (hipoesplenismo, alteração do sistema complemento e áreas de necrose óssea).

A osteomielite é mais comum na região diafisária dos ossos longos, em particular do fêmur, da tíbia e do úmero. O microrganismo mais encontrado é Salmonella, seguido por $S$. aureus e bacilos entéricos Gram-negativos ${ }^{(3,8)}$.

Embora menos comum que os infartos ósseos, o diagnóstico diferencial entre essas duas condições é freqüentemente difícil, pois como mencionado anteriormente, nas duas condições o paciente pode apresentar dor, edema, eritema, febre e alterações sangüíneas. 
Achados radiográficos de osteopenia e periostite não são específicos e podem ser encontrados em ambas as condições. Áreas radioluscentes intra-ósseas são identificadas mais tardiamente nos quadros infecciosos ${ }^{(3)}$. À ressonância magnética, a osteomielite apresenta alto sinal nas imagens ponderadas em T2 e STIR. A seqüência mais sensível e específica é a ponderada em Tl com saturação de gordura e após injeção endovenosa de meio de contraste (gadolíneo), em que essas áreas quase sempre sofrem realce ${ }^{(5)}$. Infelizmente, infartos medulares podem ter características de sinal muito similares, não sendo sempre possível o diagnóstico diferencial ${ }^{(1)}$. Acreditava-se que as anormalidades das partes moles adjacentes, como edema e realce de periósteo, músculos, fáscias e gordura subcutânea, indicassem o diagnóstico de processo infeccioso, porém também podem estar presentes nos casos de infartos ósseos ${ }^{(8,11)}$.

O diagnóstico definitivo, portanto, só é possível por meio de dados clínicos e culturas positivas (sangue ou osso

\section{REFERÊNCIAS}

1. Lonergan GJ, Cline DB, Abbondanzo SL: Sickle cell anemia. Radiographics 21: 971-94, 2001.

2. Manual de diagnóstico e tratamento de doenças falciformes Agência Nacional de Vigilância Sanitária, $1^{\text {a }}$ edição, 2002.

3. Almeida A, Roberts I: Bone involvement in sickle cell disease. Br J Haematol 133: 212-4, 2005.

4. Umans H, Haramati N, Flusser G: The diagnostic role of gadolinium enhanced MRI in distinguishing between acute medullary bone infarct and osteomyelitis. Magn Reson Imaging 18: 255-62, 2000.

5. Vicari P, Achkar R, Oliveira KRB, et al.: Myonecrosis in Sickle Cell Anemia: case report and review of literature. South Med J 97: 894-6, 2004.

6. Amundsen TR, Siegel MJ, Siegel BA: Osteomyelitis and infarction in sickle cell hemoglobinopathies: differentiation by obtido de aspiração ou biópsia), restando à ressonância magnética importante papel na localização das lesões e monitoramento do tratamento ${ }^{(1)}$.

\section{CONCLUSÃO}

Os métodos de diagnóstico por imagem são parte importante no manuseio de pacientes com anemia falciforme, sobretudo na avaliação das freqüentes complicações musculoesqueléticas. Neste contexto, a radiografia simples pode mostrar aspectos característicos da doença, como o crânio com estriações perpendiculares e a vértebra "em H" e contribui para a detecção de infartos ósseos em fases mais avançadas. A ressonância magnética é de grande valia na detecção precoce das alterações osteoarticulares, além de contribuir para monitoramento e acompanhamento das infecções, podendo também detectar alterações em partes moles, como infartos musculares.

combined technetium and gallium scintigraphy. Radiology 153: 807-12, 1984.

7. Bonnerot V, Sebag G, deMontalembert M, et al.: GadoliniumDOTA enhanced MRI of painful osseous crises in children with sickle cell anemia. Pediatr Radiol 24: 92-5, 1994.

8. Crowley JJ, Sarnaik S: Imaging of sickle cell disease. Pediatr Radiol 29: 646-61, 1999.

9. Frush DP, Heyneman LE, Ware RE, Bisset III GS: MR features of soft-tissue abnormalities due to acute marrow infarction in five children with sickle cell disease. AJR 173: 989-93, 1999.

10. Ataga KI, Orringer EP: Bone marrow necrosis in sickle cell disease: a description of three cases and a review of the literature. Am J Med Sci 320: 342-7, 2000.

11. Babhulkar SS, Pande K, Babhulkar S: The hand-foot syndrome in sickle cell haemoglobinopathy. J Bone Joint Surg Br 77: 310-2, 1995. 